\title{
Healthcare is Undergoing Profound Changes, driven by Technological and Informatic Advancements, Demographic Shifts, and Changing Lifestyles throughout Europe
}

\author{
Jacqueline Rudolph Germain* \\ European Medical Association, Belgium
}

*Corresponding author: Jacqueline Rudolph Germain, Administrative assistant, European Medical Association, Avenue des Volontaires, 19,1160 Brussels, Belgium

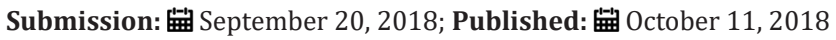

\section{Introduction}

Bioscience and technology are increasing the understanding of the human body and mind, and the ways in which injuries, conditions and diseases can be prevented and treated. Health professionals will be required to keep abreast of these developments as they manifest themselves in new equipment, treatments and prevention. Technological advancements such as big data continuously expand the potential of health professionals in clinical decision-making and advance care delivery. To reflect on these developments, a consortium of 13 partners was pulled together to join a diverse range of expertise to develop new training opportunities for health-care professionals, including medical doctors, in which they are offered courses and training opportunities to learn about these technological developments and their application in their daily work-practice.

The partners of this consortium represent expertise from $8 \mathrm{Eu}-$ ropean Union member states, with background from bioinformatics and genomics research and development via course developers and organizers to medical professionals. The project uses the experiences not only from public and private universities, but also SMEs and large companies representing all major sectors of the European economy. This way, in addition to the high quality and timeliness of the developed course material, it is also ensured that it can be delivered in modern, efficient, and flexible way to the interested target audience.

The first major phase of the BioS project started in the January of 2018 and runs for 18 months. During this time frame, a modular curriculum is developed with the contribution of partners with closer hands-on experiences with bioinformatics training. The four planned modules will cover

1. Basic introductory material about bioinformatics methods, tools, and resources relevant for the medical practice.

2. Computational statistics skills for clinical doctors, focusing on the correct interpretation of biomedical data and basic knowl edge on the use of appropriate methods to assess statistical significance. A dedicated module will demonstrate how to use commercial personalised genomics services in patient care. These services are already available worldwide and medical professionals should utilize their services in practice. For that, knowledge and skills from the first two modules are turned to practical applications using real life examples. In this module information and training on how to interpret disease risk and which are the optimal genomic studies for each situation is also provided.

3. The final module of the curricula is dedicated to communication and ethical relevance's of these new methodologies for health practitioners. Since personalized genomics and other bioinformatics services are known to handle sensitive information about patients, it is very important that proper communication and attention is paid to these aspects. The module also includes training activities on genetic counselling, risk management and decision making.

The finalized curricula will be developed to training material consistent with the relevant guidelines of the European Union, especially with the European Qualification Framework (EQF) and the European Credit System for Vocational Education and Training (ECVET). The material will include video tutorials, wrap-up videos and modern learning material including media, Internet and audio resources, PowerPoint or "articulate" presentations. Further, a training handbook for both trainers and trainees will be developed to assist the delivery of the program. All training and supporting material will be available in English, and the all consortium languages (Greek, Portuguese, Italian, Spanish, German, French, and Finnish).

During the second phase of the project, a system for testing and delivering the course material will be developed until December 2020, the end of the project. The BioS Virtual Learning Environment (VLE) will be produced by partners with experience in integrated 
systems development. The courses will be tested on a panel of 80 medical doctors using the work-based learning approach, including opportunities to apply knowledge in practical "real life" workplace situations, and embedding trans-national learning experience.

Table 1: *The partner organisations are Association Medicale Europenne, Belgium German Oncology Centre, Cyprus efficiency of modern healthcare services in European Union member states, therefore enhances the quality of life of European tax-payers.

\begin{tabular}{|c|c|}
\hline $\begin{array}{c}\text { Enios Applikations (e-NIOS), } \\
\text { Greece }\end{array}$ & EUREHVA GmbH, Germany \\
\hline Olympic Training, Greece & BG Klinikum Murnau, Germany \\
\hline Skybridge Partners, Greece & FOR Di Paolo Tubino \& C. SAS, Italy \\
\hline $\begin{array}{c}\text { Associació Bioinformatics Bar- } \\
\text { celona, Spain }\end{array}$ & HiDucator Oy, Finland \\
\hline
\end{tabular}

\begin{tabular}{|c|c|}
\hline University of Patras, Greece & $\begin{array}{c}\text { Escola Profissional do Alto Lima, } \\
\text { Portugal }\end{array}$ \\
\hline $\begin{array}{c}\text { Association Medicale Euro- } \\
\text { penne, Belgium }\end{array}$ & German Oncology Centre, Cyprus \\
\hline
\end{tabular}

At the end of the BioS project, an entirely new training opportunity will be open for healthcare professionals in Europe, who will be able to utilize the latest technological developments in computational biology and bioinformatics in their daily activities. This way BioS directly enhances the quality and efficiency of modern healthcare services in European Union member states, therefore enhances the quality of life of European tax-payers (Table 1).

\section{Acknowledgement}

13 partner organisations* from 8 European countries successfully started the 3 years project "Digital skills on Computational Biology for Health Professionals" (BioS). This project is co-funded by the Erasmus+ Programme of the European Union.

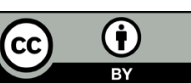

Creative Commons Attribution 4.0 International License

For possible submissions Click Here
Submit Article

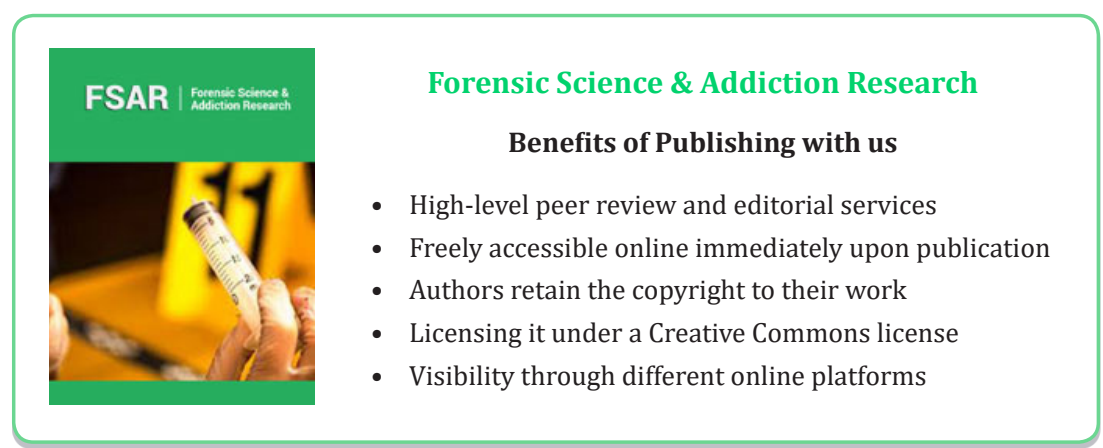

